\title{
Medicine in Society*
}

\author{
WALPOLE LEWIN
}

British Medical fournal, 1975, 3, 523-526

The senior professions of the Church and Law have always had prestige enough to enable each of them to keep a finger firmly and consistently in the governmental pie. They have therefore been able to see to it that any duty that was laid upon them should be set off by a corresponding privilege or immunity. The lowly and junior profession of Medicine, unlike its proud elder sisters, has had no direct part and no direct influence in the work of government. It has therefore had to submit to its duties being piled up as occasion arose with no resource for securing a due compensation of privilege and immunity except such slender sense of natural justice as governments possess and their occasional doubts about the prudence of overloading a willing beast. These resources have shown all the ineffectiveness we might have expected. The result is that at a time when it is no longer possible to conceal the wholly unique importance of medicine for the very existence of social life, that profession finds itself of all professions the last in command of social prestige, the least privileged, the most exposed and the hardest worked. ${ }^{1}$

Some of you may feel that this could have been written today, but it is in fact a quotation from Wilfred Trotter's address to senior students and junior practitioners at University College Hospital in 1933, over 40 years ago. It is interesting to reflect that such comments could be made at a time when by comparison with today the medicopolitical climate was quiet. The period between the two world wars was a watershed in medicine between 19 th century medicine, with its very personal services

* Based on an address delivered to the Manchester Medical Society on 7 May, 1975.

Department of Neurological Surgery and Neurology, Addenbrooke's Hospital, Cambridge CB2 2QQ

WALPOLE LEWIN, M.s., F.R.c.s., Consultant Neurological Surgeon offered to some by physicians and general practitioners, and the emergence of the specialties together with a growing awareness that the arrangements for medicine were no longer sufficient for society as a whole. The working of the 1911 Health Insurance Act was seen as only a very partial solution to the problem. The growing difficulties of the voluntary hospitals, established originally for the sick poor, made the need for a reassessment of our hospital services apparent. After the second world war the economic difficulties and the financial implications of the rapid advances in medicine made change inevitable.

When Trotter spoke the British Medical Association was already pressing for an extended health service, which culminated in a joint report from themselves and the Royal Colleges in 1940 , in which the elements of our present National Health Service were outlined. In 1942, under a national government, the Beveridge Report, ${ }^{2}$ which was a financial blueprint for the service, was published. Finally, under a socialist government with Aneurin Bevan as Minister of Health, our present N.H.S. came into being in 1948. Whatever its faults few would deny that the N.H.S. was a major social and humanitarian contribution to society which has benefited millions of people and of which we can be justly proud.

We have also seen the growing influence of world governments in health problems through such bodies as the United Nations Assembly, the World Health Organization, and, more recently, the European Economic Community. In other words governments have now accepted, "the unique importance of medicine for the very existence of social life." We would applaud this growing social conscience but the profession, nursed for centuries in an essentially personal medicine-a doctor/patient relationship-would be wise to examine what implications there may be for the profession arising from these changes, and what further duties emerge. This address is concerned with some aspects of this situation both at home and abroad. Not that the underlying difficulty is new: the age-long problem of what is an acceptable balance between the advantages of social cohesion and the value of individual action and initiative on which the development of a society depends. 


\section{Organization of Health Care in the U.K.}

The time-honoured Hippocratic Oath was redefined in the declaration of Geneva by the World Medical Association in 1948 and amended in the Sydney declaration of 1968 . These statements refer to an individual relationship-there is no record of Hippocrates running a regional health service. It is also true that no government in this country has sought to interfere with this relationship directly. But do, in fact, the present demands of society have any impact on this relationship ? There are doctors who believe that this is not so and that there is no need to concern themselves with the wider issues outside. But a moment's reflection will show that the progressive organization of health care may indeed affect this relationship and the doctor is called on to develop those measures which are beneficial to the public as a whole, while at the same time preserving his independence of action in relation to an individual patient.

In this country the N.H.S. has put into the hands of government the provision of resources. If there was no limit on manpower or finance this might matter little, but when resources are limited this means in practical terms a limitation of what can be provided for an individual patient. The Sydney declaration states that a doctor owes to his patient "complete loyalty and all the resources of his science." Or, as stated in the Nuremberg Charter drawn up by the doctors in the E.E.C. in 1967 when considering the implications of the Treaty of Rome, "The unique doctor/patient relationship which is necessary in itself, recognises that both parties belong to a community and this is a prerequisite of any health and welfare policy. There must be, however, mutual trust between the patient and his doctor based on the fact that the doctor's actions are governed by the overriding value he places on the human being to whose service he conscientiously devotes all his knowledge. Whatever his type of practice and remuneration, the doctor in the practice of his profession must be able to make his decisions freely, taking into account both the interests of his patient and the firm possibilities available through the medical knowledge and techniques he has acquired."

We have to equate these beliefs with the practical situation. For example, a doctor advises a patient to enter hospital. But there is a waiting list which derives not solely from the doctor and his patient but it is a measure of the inadequate resources available from government to meet the doctor's desire to do the very best for his patient. Again, one of the advantages of the N.H.S. has been to distribute specialist skills and new advances in medicine more evenly over the country. But no one would pretend that this is by any means uniform. Indeed the limitation of resources has been the subject of comment in a recent memorandum from the Presidents and Deans of the Royal Colleges and Faculties (1974), ${ }^{3}$ which outlines their fears that short of the ability in the future to preserve present standards in medicine there is now a risk of their falling.

Clearly, in such a situation we come to priorities in medicine and who is to decide such priorities. Difficult as this may be, if the doctor is to maintain his independence he must take part in determining these priorities so long as resources are limited. Nor does the problem of what and how much to provide for a patient end with a resolution between the Department of Health and Social Security and the profession. There are at times cogent pressures from other quarters. For example, the early introduction of cervical cytology with its call on additional medical manpower came largely from lay pressure. The abortion law is an example where a political decision on behalf of society had immediate implications on the doctor/patient relationship. This relationship may be affected in other ways. Thus, it may not be sufficiently realized that it could be influenced by the current Royal Commission which is considering civil liability and compensation for personal injury. They have included in their programme a category to discuss whether in relation to medical practice the present tort system should be replaced or supplemented by a no fault scheme under which a patient could be compensated in respect of an accident (interpreted in the widest sense) during the course of medical treatment. It is obvious that the medical profession has to submit evidence on this point since such a system would change the patient/doctor relationship. These suggestions could mean that if medical treatment is not successful or a complication arises there could be a basis for no fault compensation. This would change the pattern of medical practice where a doctor sets out, within his knowledge, to do his best for his patient. A no fault system might well deter a doctor from undertaking procedures which would be in the best interests of a patient but would carry a higher risk in the knowledge that compensation might follow and reflect adversely on him.

The freedom of the patient in this relationship has also to be preserved. Thus the recent proposals for the private sector of medicine will need to be carefully considered. The Secretary of State for Health and Social Security has announced in the House of Commons impending legislation leading to the abolition of private beds in the N.H.S. and, more than this, measures designed to limit private practice outside the N.H.S. Thus, assuming her role as guardian of the health of the nation, the Secretary of State intends to use her powers to review the licensing of all nursing homes and private clinics, the granting of planning permission for new buildings, and the use of N.H.S. facilities in the private sector.

If these proposals are carried through it could mean the severe limitation and ultimate virtual withdrawal of a viable alternative service to the N.H.S. What then becomes of the individual freedom of a patient to seek if he wishes the medical care of his choice, and where will the patient obtain a further opinion on what for him may be one of the most important decisions of his life ? Even leaving aside the damage the separation of the private sector will do to the N.H.S. the limitation of free choice for the patient implied in these proposals would present the most blatant intrusion by government into individual liberty and professional freedom that has been seen for a very long time.

The doctor in society today, therefore, has to be aware that around the central core of a patient/doctor relationship are major influences developed in the name of society as a whole which affect his practice. Nor is medical research immune to increased bureaucratic interest. The Rothschild Report on a framework for government research and development, ${ }^{4}$ which proposed that a proportion of research councils' budgets should be turned over to project-oriented research on a customer/contractor basis for the health departments gave rise to a good deal of comment in medical and other scientific circles. The medical profession could not accept that research can be divided simply into two categories-basic and applied-but that there are numerous examples where the two are indivisible. In welcoming some of the proposals in the Rothschild Report, it urged that the arrangements should make quite certain that the research councils should remain independent and that their applied research should not be confined to contracts from a government department. A compromise was reached, but this was a good example where society through government wished to direct interests to those areas which it felt would be of more immediate benefit to them. But the professions, while accepting the further co-operation with government, had to make it clear that research has to remain independent, cannot be easily compartmentalized, and cannot be limited by contract.

\section{Competence to Practise}

Over the years society has seen the advantage of maintaining the independence of the medical profession, while at the same time developing a structure by which it could be assured of a standard of competence. For many years this has been satisfied largely by the requirements of basic qualification and the higher degrees and diplomas from universities and Royal Colleges and Faculties to recognize specialization. More recently there has been a growing interest in continuing competence to practise once these processes have been completed, to satisfy on the one hand the wishes of the profession to be seen to be faithfully preserving and developing their own standards and on the other the desire of society, in those countries whose health care is primarily on private insurance or fee for service schemes and in those with a state medical service, for some check other than the hitherto regulatory process by which a doctor's practice was determined by the estimate of his patient.

The doctor would be unwise to ignore these pressures though his anxiety over possible limitation of his professional independence after training is understandable. The profession was right, however, to set up in 1973 its own committee "to review the present methods of ensuring the maintenance of standards of continuing competence to practice, and of the clinical care of patients, and to make recommendations." We await its findings. In the meantime the Committee of Inquiry into the Regulation of the Medical Profession (Merrison Report) has commented briefly on this situation in a section entitled "Relicensure," "We state here our view that the education of a doctor is a continuing process which does not end even at the specialist registration level, but ought to continue to his retirement. Unless a doctor keeps abreast of medical developments it is likely that his competence as a medical practitioner will be seriously affected. There is growing interest in this country in schemes of tying continued registration to periodic tests of competence. Though we have been impressed by some of the evidence from abroad which we have seen, we have not felt able to recommend the introduction of any scheme of relicensure. This is sufficiently important and complex a matter to 
warrant a separate inquiry of its own. The introduction of relicensure schemes would represent an enormous change in approach to regulation and could be recommended only on a firm foundation of evidence. We do not, however, wish to prejudice the consideration of schemes of relicensure especially because the medical profession is in fact mounting its own enquiry in this field." We should applaud this committee for awaiting the professional view on a matter which so directly involves the doctor/patient relationship.

\section{International Influences}

Medical practice is influenced not only by changes at home but by political and social influences abroad. The World Health Organization is a specialized intergovernmental agency of the United Nations charged with the task of international health work. Through its advisory services it helps member governments to develop their health services. Some 135 states are members and there is an annual budget of about $£ 50$ million. Over the years it has done sterling work in environmental health and health education in the interests of society as a whole. One such example is the success of its smallpox eradication programme, which culminated in the recommendation from the Department of Health and Social Security in 1972 that routine vaccination in this country be no longer compulsory except for certain designated groups. Among the current topics the World Health Organization is examining are the ethics of clinical research It is essential, therefore, that in all matters which relate to medical practice the profession should take a full part in these deliberations since it is becoming increasingly obvious that, with a shrinking world, such decisions can have an immediate impact on individual practice.

The United Nations General Assembly passed a resolution last year indicating their intention to debate at their 5th Congress on Crime and the Treatment of Offenders in June, 1975, the problems of torture and other matters in relation to detention and imprisonment. The ethical problem for doctors involved in these situations in relation to the detainees as their patients is a real one. The B.M.A., after the disturbances in Northern Ireland, prepared a document in 1974 on the involvement of doctors in interrogation procedures and in artificial feeding of prisoners. They have recommended that no doctor should take part, directly or indirectly, in interrogation procedures and that in relation to artificial feeding a prison medical officer must have complete clinical independence in deciding on the care of a prisoner for whom he has medical responsibility. This latter view was supported by the Home Secretary in a statement of 17 July, 1974. The United Nations Assembly has indicated that it wishes documents on the matter to be prepared by governments through the World Health Organization. We would take the view that the opinions of the practising profession should be clearly stated and submitted to the United Nations unamended on the grounds that this is a matter which affects directly a doctor's professional relationship. Fortunately, a draft document expressing the views of national medical association was prepared by the World Medical Association and with the cooperation and help of the World Health Organization was placed before the 5th Congress.

A third body now has particular importance for us-the European Economic Community. The Community is a union seeking to establish a common market and progressively approximating the economic policies of member states. To these ends the Community seek free movement of goods, capital, and labour. Not envisaged in the Treaty of Rome $1957,{ }^{6}$ but a possible development for the future is a closer political union. You may think it strange from this description that doctors should be included in such a document. But free movement includes most people, and the medical profession is specifically mentioned in article 57. This article charges the Community's Council to issue directives for the mutual recognition of diplomas, certificates, and other evidence of formal qualification to make it easier for persons to take up and pursue activities as self-employed persons. The Commission in Brussels is charged with implementing the Treaty but it does not include the representatives of the practising profession. Decisions are made by the Council of Ministers advised by the appropriate government departments. In such a venture the medical profession is a very small fish in a very large pond and at risk from the compromises which may be necessary from time to time to reach agreement. It should also be noted that the medical profession was chosen as the first professional group for which an appropriate directive should be developed.

The national medical organizations of the original six countries quickly recognized the dangers ahead and in 1959 set up the professional Standing Committee of Doctors of the E.E.C. In 1973 they were joined by the United Kingdom, Eire, and Denmark. Over the last two years the nine member states have examined the proposed directives in great detail to satisfy the remit of the Treaty of Rome to allow free movement of doctors and to recognize the equivalence of qualifications and establishment, but at the same time to seek ways by which the profession can be assured of itself maintaining its own standards and discipline. The Standing Committee is not a statutory body and its influence with the Commission has to be sought on the thesis that whatever may be agreed by governments is likely to be translated into action only if the support of the practising profession is secured. The progress of this long debate has been followed with more than usual interest by other professional groups such as lawyers, dentists, veterinary surgeons, pharmacists, accountants, and bankers, whose directives will follow and who similarly will wish to see what safeguards can be included to preserve their own professional independence. The medical directives were finally approved by the Council of Ministers in March 1975 (all countries had signed by June 1975).

What has been achieved by the Standing Committee of Doctors, which was not envisaged in the earlier drafts ? Included in the agreed directive is one matter of the greatest importance: the preservation of the profession's right to maintain its own standards by the setting up of a professional advisory committee to advise on standards of both undergraduate and postgraduate education and the equivalence of qualifications. On the committee will be representatives of the practising professions and the universities to whom the Commission will turn for advice. Also included in the directives are qualitative criteria for basic training; a reference to the possible development of general practice as a specialty, though its standards have still to be defined; part-time training (particularly relevant for our women doctors and others in this country) is accepted; and an arrangement for the host country to be satisfied as to the language attainment and knowledge of the health organization of the host country of the incoming doctor. That it has taken so long to achieve these agreements illustrates the difficulties confronting a profession negotiating in an essentially political atmosphere and also how much more remains to be done in the future.

It is necessary, therefore, for national and international medical associations to be vigilant in the study of these emerging social documents and to guard against the erosion of a doctor's medical responsibility arising from decisions, however well meant. But the outcome is vital to the profession.

\section{The Professional Voice}

These illustrations from home and abroad show the development of the social conscience in relation to health. The march towards an egalitarian society attracts the interest of many individuals, groups, and governments in health care. Such integration and organisation can have advantages for society as a whole, but we should be aware of the attendant risk of blunting individual effort and initiative. The reorganization of the N.H.S. has among its prime aims delegation downwards and accountability upwards. What we have seen so far is largely the delegation downwards of central policies and accountability upwards of a predetermined budget. The desire at the periphery that all those with an interest in health problems both lay and medical should have a voice leads to a multiplicity of interlocking committees and decision by consensus. Certainly the benefits of such co-operation have to be developed. But we also need to ensure that we do not take away responsibility from the individual, nor make it difficult for an individual or a group to pursue a new approach to a problem which may be more relevant to the local circumstances because of the overriding need for a peripheral consensus or acquiescence to central direction. A society can be maintained by the efforts of a benevolent government, but it can only develop if it promotes and is susceptible to individual initiative.

In the new society a doctor's responsibility cannot end with his preservation of the doctor/patient relationship and a defence of the independence of a profession. He also has a responsiblity to society as a whole in advising on health care problems in general. These may range from particular issues in which he alone may be competent to judge to his role as an educated man in advising not only on the allocation of available resources within the N.H.S. but also on how best the nations should use its resources as a whole to improve its health. Can this, for example, necessarily be secured only by the amount we spend on medical services, or do we accept that proper housing and adequate education are as important. The doctor is in a unique position in this respect, and whether or not he will be listened to by laymen will depend not on any authority he may assume to have but on the quality of his leadership. 
We cannot assume the independence of medicine as some immutable right deriving from an inbuilt authority in medicine. The place of the doctor in society is questioned in every generation. That he has retained his position is due to the fact that he has been ready to examine with the society in which he finds himself how best the wishes of society can be matched with the ideals of his own profession, both he and they reconizing that medicine and the patient/doctor relationship need, for the benefit of the public, to be independent. In the last analysis this independence is conferred by the public, and the authority the medical profession has and the leadership it gives in society rests not on any elitism, but is accepted by the public so long as they are satisfied with the intellect, integrity, and internal discipline of the profession. In other words, though we have broad principles to guide us, the patient/doctor relationship needs to be scrutinized as new societies emerge, and professional independence is earned and used for the benefit of the public and the profession alike.

In this country there are three principal organizations to help the profession in carrying out its tasks. The General Medical Council concerns itself with the standards of basic medical education and the ethics of the profession, deriving this authority from the acquiescence of the profession and agreement of the public through the Privy Council and Parliament. The Royal Colleges and Faculties are concerned primarily with maintaining and improving the standards of medicine and the development of its science, but again, as charitable institutions, finally derive such authority as they may possess from the support given to them by the public, who over the years have seen the advantages of such matters being left firmly in the hands of bodies independent of government and political influence. The third group of bodies are the medical associations of which the British Medical Association is the largest. Though one of its main concerns is the interests of doctors it is also charged with the duty to promote the art and science of medicine. Such authority as it may possess to speak for doctors derives from the fact that it is a voluntary association. That most doctors choose to belong to such an organization is a powerful influence both in its relations with the public and with governments. In contributing to the maintenance of the independence of the profession the British Medical Association is complementary to the other bodies already mentioned. By concerning itself with the many problems arising out of our involvement in the N.H.S. and the several international influences on health care that have been mentioned in this paper it fulfils a role that cannot be fully carried out by the General Medical Council, because of its statutory limitation, or the Royal Colleges and Faculties, because of their charitable status. These three groups together, therefore, serve as guardians of the medical profession and of medicine, and it is essential that they should work together in partnership.

The multidisciplinary nature of modern medicine and its involvement with some of its sister professions in discussing social issues of the day raise the question whether the time has come for the professions in this country to seek a common front to make sure that individual effort and initiative, from which new knowledge comes, is preserved through the continuing independence of the professions and not truncated in an increasing bureaucracy; that as a knowledgebased society the voice of the professions in this country on major issues should be heard with the same clarity as other more obviously organized groups. This may be true. It is undoubtedly true that while there are healthy differences within our own profession on many issues the prime need of the profession today is to secure unity on the broad issues if it wishes to influence society.

\section{Conclusion}

The public are well aware that the independence of the profession works in their own interest, both in the patient/doctor relationship in the clinical field, and by ensuring that individual effort, new ideas, and research, on which the development not only of medicine but of society as a whole depends, is not stultified. We accept in our turn the need to define and maintain our own standards and discipline. But we also have a duty to be sensitive to the aims and wishes of society and to help in reaching a satisfactory compromise on the problem posed at the beginning of this address - that is, the advantages and benefits of social cohesion and the preservation of individual initiative and enterprise. To do this we have to reach a true partnership with those whose responsibility it is to organize and provide for health care. The government of the day can expect from the medical profession its co-operation in the development of health services in the broadest sense. But in its turn the profession should expect equal concern from government to preserve the independence of medicine. Provided we are clear on the basic philosophy that guides our great profession we can reach acceptable solutions. But should this philosophy be challenged -if the fire is kindled-we must not fear the flame.

\section{References}

1 Trotter, W., Collected Papers, p.3. Oxford University Press, 1941.

2 Social Insurance and Allied Services (Beveridge Report), Cmnd. 6404. London, H.M.S.O., 1942.

${ }^{3}$ Royal Colleges, British Medical fournal, 1974, 4, 237.

4 Organization and Management of Government Research and Development (Rothschild Report), Cmnd. 4814. London, H.M.S.O., 1971.

${ }^{5}$ Report of the Committee of Inquiry into the Regulation of the Medical Profession (Merrison Report). Cmnd 6018. London, H.M.S.O., 1975.

6 Treaty Establishing the European Economic Community, Cmnd. 4864 London, H.M.S.O., 1972. 